\title{
Expectations and experiences of final-year medical students regarding family medicine rural rotations: Influence on intention to practise in a rural setting
}

\author{
N Beckett, ${ }^{1}$ MB ChB, BSc, BSc Hons Med Sc, PGDipFM; \\ R Delport, ${ }^{2}$ BSc (Nursing), BCur Hons (Intensive Care Nursing), MSc (Medical Physiology), PhD (Chemical Pathology), MEd (Computer-assisted Education) \\ ${ }^{1}$ Division of Family Medicine, School of Public Health and Family Medicine, Faculty of Health Sciences, University of Cape Town, South Africa \\ ${ }^{2}$ Health Sciences Skills Laboratory, Faculty of Health Sciences, University of Pretoria, South Africa
}

Corresponding author: N Beckett (nazlie.beckett@uct.ac.za)

\begin{abstract}
Background. During recent years, a shortage of medical practitioners has been reported in rural underserved areas of South Africa (SA). The Division of Family Medicine, Faculty of Health Sciences, University of Cape Town (UCT), SA, implemented a voluntary 4-week rural rotation in Vredenburg, West Coast District, in 2011 in response to the need for rural training to be included in the medical curriculum. The reason for the decline in the number of students making use of this opportunity, is unknown; therefore, a compulsory 1-week rural rotation, as part of the final-year 4-week clerkship, was implemented in 2015. The rationale for this intervention was to ensure a sustainable rural learning environment and to highlight the need to explore students' expectations and experiences with regard to the rural rotation.

Objectives. To explore the expectations and experiences of 6 th-year medical students regarding the family medicine rural rotation, and to identify factors that may influence return to a rural setting after graduation.

Methods. A qualitative study design was used. Sixth-year medical students ( $n=31)$ participated in the pre-rural focus group discussions (FGDs), and 28 in the post-rural FDGs. A content analysis method was used to identify key themes.

Results. Key themes for student expectations included programme content, clinical experiences, language barriers and physical environment. Themes for student experiences related to environment and resources, programme content and clinical experience, language barriers and logistics. Positive experiences included good mentorship, autonomy to perform procedures and improved preparedness for internship. Negative experiences included inadequate clinical exposure and time allocation. Most students expressed an intention to enter rural practice; reasons included effective teamwork and making a difference. Conclusions. Student expectations of the rural rotation varied from feelings of apprehension about language barriers to programme content and clinical experience. However, the majority were excited about the potential clinical exposure in a rural setting. Positive experiences related to student expectations being met and working independently while supervised by good mentors. Based on these findings, it can be concluded that all medical students, irrespective of geographical background, should be exposed to rural medicine in the undergraduate curriculum.
\end{abstract}

Afr J Health Professions Educ 2019;11(1):3-5. DOI:10.7196/AJHPE.2019.v11i1.1071

The literature indicates that there is a shortage of medical practitioners in rural underserved areas of South Africa (SA). Of SA's 49 million residents, $\sim 46 \%$ are served by only $12 \%$ of our doctors, mostly in the public sector. ${ }^{[1]}$ Reasons that have contributed to this include doctors who emigrate, as well as lack of recruitment of doctors for rural placement after qualification. ${ }^{[1]}$ In response to this phenomenon, the training of undergraduate medical students to practise in rural communities was defined as an educational priority. ${ }^{[2]}$

Medical education in SA is entering 'exciting times. ${ }^{[2]}$ Educational institutions in Australia, Canada, the USA and SA are addressing the need for training of practitioners in rural areas by providing students with opportunities for exposure to rural health experiences. ${ }^{[2]}$

The Division of Family Medicine, Faculty of Health Sciences, University of Cape Town (UCT), SA, implemented a voluntary, rural clerkship in the West Coast District of Vredenburg in 2011. In 2014, there was a decline in student recruitment numbers. Therefore, to ensure sustainability of the rural rotation, the family medicine clerkship was adapted. Since January 2015 , all final-year students rotating through family medicine complete a 1-week mandatory rotation in the rural district hospital and community clinic in Vredenburg. They return to the urban setting to complete the remaining 3 weeks, based at community health clinics. The aim was to expose all students to clinical activities in a rural setting to sensitise and develop an interest in rural medicine as a career. This is based on a study by Critchley et al. ${ }^{\left[{ }^{[3]}\right.}$ which confirmed that $70 \%$ of students who completed a course in rural health showed an interest in rural health practice. It may be argued that 1 week is not sufficient to enable students to benefit from the rural experience. However, there is some support in the literature for this innovation. In a qualitative study by Adams et al. ${ }^{[4]}$ at an Australian medical school, a rural placement was defined as a minimum of 1 week in a rural location, which was associated with the current area of study.

The aim of this research project was to explore the expectations and experiences of final-year medical students regarding the rural rotation for family medicine, and to identify factors that may influence UCT students to practise in a rural setting after graduation. 
This research is relevant, as students are the key role-players who will be ambassadors to promote the rural programme, and the study findings inform future logistical planning of the family medicine programme to ensure a sustainable rural learning environment.

\section{Methods}

Final-year medical students at the Faculty of Health Sciences, UCT, were invited to participate in this study during their family medicine rotation. Informed consent was obtained, and students were notified that the primary investigator (PI) conducting the research is also the course convenor. A convenience sampling method was used. Seventy-one students in their family medicine rotation from July to October 2015 were eligible, and all students who gave consent were included $(n=31)$. Data were collected during focus group discussions (FGDs), which were conducted by the PI at the Faculty of Health Sciences. Each participant was allocated a specific code, which was linked to the responses. FGDs were conducted before and after rural rotations. Three probing questions were asked: 'What are your thoughts/expectations about the rural rotation for family medicine?', which was used to initiate discussion during the pre-rural FGDs, and 'What were your experiences regarding the rural rotation?' and 'Based on your experience, would you consider returning to a rural setting after you qualify and why?', which were used for the post-rural discussions. The PI recorded the FGDs and a moderator took notes. Transcribed data were available to participants for member checking. Data pertaining to the expectations and experiences of the students were captured on an Excel spreadsheet. Data were grouped into common categories and allocated a specific code. A content analysis method was used to identify key themes, and data were analysed until saturation was reached. Data from the second probing question used in the post-rural FGDs were transcribed verbatim and analysed to identify factors that may influence return to a rural ractice. Demographic data were obtained from UCT's undergraduate student office, which were recorded in categories to identify age, sex and area of origin of the participants. These data were used during the analysis of results pertaining to intent to return to rural practice. Each quote used in this article is referenced to the participant.

\section{Ethical approval}

Ethical approval was obtained from the Human Research Ethics Committee at UCT (ref. no. HREC 336/2015). Permission for student participation was received from the student affairs office.

\section{Results}

Thirty-one students participated in the FGDs conducted before the rural rotation and 28 students in the post-rural FGDs. Three students were lost to follow-up in the post-rural discussions owing to logistical reasons.

The participants' ages ranged from 22 to 33 years. The majority were female $(n=21)$, and participants were from Western Cape Province $(n=16)$, KwaZuluNatal Province $(n=6)$, Gauteng Province $(n=2)$, Limpopo Province $(n=2)$, Mpumalanga Province $(n=2)$, White River $(n=1)$ and North West Province $(n=2)$.

\section{Main themes related to student expectations Programme content and clinical experience}

A few of the students expected it to be a new and varied experience and felt apprehensive about resources, but were keen to implement clinical knowledge into practice:
'I am looking forward to seeing a new population with a range of conditions compared to urban patients.' (5.10)

'Exposure to a smaller environment with more generalised illness, with limited resources. Being sparing with ordering of investigations.' (3.1)

Language barriers, feelings and emotions and physical environment Some students were concerned about language barriers, and emotions ranged from excitement to apprehension, while others had no specific expectations but were willing to adapt:

'I am worried about the language because I do not speak Afrikaans.' (4.1) 'I don't expect it to be "really rural" where you go into the community ... not like KZN.' (2.1)

\section{Themes related to student experiences}

Themes identified for experiences were closely linked to student expectations and related to environment and resources, programme content and clinical experience, language barriers and logistics.

\section{Programme content and clinical experience}

Students found the participation rewarding and gained good clinical experience regarding the rural health system and referral patterns. Others found the experience frustrating because of lack of patients during quiet casualty calls and limited time in Vredenburg:

'If we had better exposure for longer ... we would have a better opportunity to work in a team. It would have been better to go for 2 weeks, with more clinical time immersed in outpatient clinics.' (1.2)

\section{Language barriers and logistics}

Students experienced issues with transport and found the language barrier to be challenging:

'Transport was a problem; it should be clear that the vehicle is for everyone.' (2.2) 'There was a huge language barrier ... patients speak only Afrikaans and notes are written in Afrikaans.' (4.9)

\section{Rural setting}

Based on students' experiences, a probing question was asked to assess intention to return to a rural setting. Most of the students (67\%) expressed an intention to return to such a setting to practise (Table 1):

'I would still go back to a rural setting ... I liked the hospital and treating patients in a community setting. I liked the autonomy and the confidence it gave me. I would be able to focus on my own interests.' (3.2)

The remaining students (33\%) indicated that they would not consider returning to rural medicine because of personal reasons, such as children's schooling and intention to specialise:

'No! I will never work in a rural area ... I have a family life. I want to specialise ... there is no place for a physician in a district hospital. I feel you get pressurised to go rural ... it is a personal choice.' (3.8)

\section{Discussion}

Students had varied expectations regarding the rural rotation. Some had spoken to peers, which influenced their perceptions positively, whereas others were anxious because of language issues and the unknown environment. Student experiences were closely linked to their expectations. 


\section{Short Research Report}

\begin{tabular}{ll} 
Table 1. Reasons for intention to return to a rural setting \\
\hline Reason & Participants, \% \\
\hline Effective teamwork & 42 \\
Making a difference & 21 \\
Safe working environment & 11 \\
Autonomous practice & 11 \\
Continuity of care & 10 \\
Manageable doctor-patient ratio & 5
\end{tabular}

Most students had a positive experience and appreciated the autonomy to work independently, but with good support and mentoring. Those who had a negative view based their opinions on their experiences in the casualty department, as there were too few patients. The majority of students (67\%) expressed intent to return to a rural setting after graduation, based on their rural experience. This is supported by evidence from a study conducted by Critchley et al., ${ }^{[3]}$ which confirmed that $70 \%$ of students who completed a course on rural health, showed an interest in rural health practice.

Some of the student recommendations were implemented in 2016, while other suggestions might be considered in future. This would ensure a sustainable rural learning environment that addresses student needs.

\section{Study limitations}

A limitation of this study was that it was conducted on one cohort of students. As Krahe et al. ${ }^{[5]}$ suggested, more research should be done to gain a better understanding of student perceptions and identification of factors that encourage rural recruitment of students to ensure sustainability of the rural rotation. It would be necessary to repeat this study with future groups of students to determine if the study findings regarding intent to return to a rural setting after graduation are supported. A future study would follow up this cohort of students to determine if intent was put into practice.

\section{Conclusion}

The objective of this study was to explore the expectations and experiences of final-year medical students regarding the rural rotation, and whether the experience influenced their intention to return to a rural setting after graduation. Based on the study findings, it can be concluded that all medical students, irrespective of their geographical background, should be exposed to rural medicine in the undergraduate curriculum.

\section{Declaration. None.}

Acknowledgements. The authors would like to thank the 6th-year family medicine students for their co-operation.

Author contributions. NB and RD designed the study; NB collected and analysed the data; $\mathrm{NB}$ and $\mathrm{RD}$ wrote the draft report; and NB reviewed the final draft for publication. Funding. None.

Conflicts of interest. The first author is the convenor of the family medicine undergraduate programme.

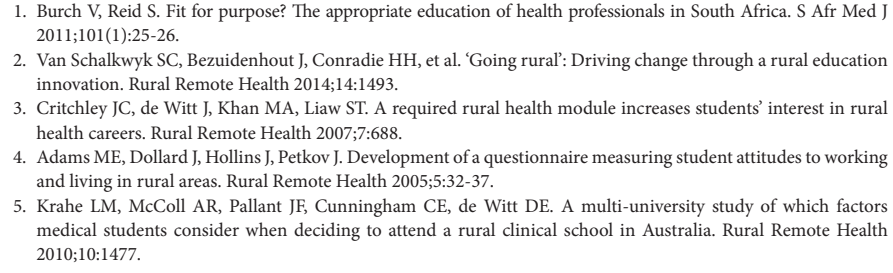

3. Critchley JC, de Witt J, Khan MA, Liaw ST. A required rural health module increases students' interest in rural health careers. Rural Remote Health 2007;7:688.

4. Adams ME, Dollard J, Hollins J, Petkov J. Development of a questionnaire measuring student attitudes to working and living in rural areas. Rural Remote Health 2005;5:32-37.

5. Krahe LM, McColl AR, Pallant JF, Cunningham CE, de Witt DE. A multi-university study of which factors medical students consider when deciding to attend a rural clinical school in Australia. Rural Remote Health 2010;10:1477.

Accepted 23 August 2018 